\title{
CRENÇAS NO AUTOCUIDADO EM DIABETES - IMPLICAÇÕES PARA A PRÁTICA
}

\author{
Antônia Tayana da Franca Xavier ${ }^{1}$, Daniela Borges Bittar², Márcia Barroso Camilo de Ataíde ${ }^{3}$
}

\footnotetext{
${ }^{1}$ Mestranda em Enfermagem Fundamental da Escola de Enfermagem de Ribeirão Preto (EERP) da Universidade de São Paulo (USP). Bolsista da Coordenação de Aperfeiçoamento de Pessoal de Nível Superior (CAPES). São Paulo, Brasil. E-mail: tayanaxavier@uol.com.br

${ }^{2}$ Mestranda em Enfermagem em Saúde Pública da EERP/USP. São Paulo, Brasil. E-mail: danielabbittar@yahoo.com.br

${ }^{3}$ Doutora em Enfermagem. Docente do Curso de Enfermagem da Universidade de Fortaleza. Ceará, Brasil. E-mail: mbcataide@ unifor.br
}

RESUMO: Este estudo objetivou conhecer as crenças que permeiam as atitudes de autocuidado dos diabéticos, sendo utilizada como forma metodológica a abordagem qualitativa. Participaram da pesquisa nove diabéticos, sendo utilizada a entrevista semi-estruturada como instrumento de coleta de dados e a técnica de análise de conteúdo, modalidade temática, para seu tratamento. Através da análise, foram encontrados três temas de significação - A influência das crenças na conceituação do diabetes; As crenças, o autocuidado e as práticas cuidativas, e A crença no papel da família, da mídia e dos profissionais de saúde no autocuidado. Constatou-se que os clientes diabéticos utilizam alimentação saudável e prática fitoterápica como forma de autocuidado; e a mídia, a família e os profissionais da saúde, são fatores motivadores do autocuidado. Portanto, para que se promova a assistência ao diabético deve-se considerar suas crenças na prática do autocuidado.

DESCRITORES: Diabetes mellitus. Autocuidado. Educação.

\section{BELIEFS IN DIABETICS SELF-CARE - IMPLICATIONS FOR PRACTICE}

\begin{abstract}
This study aimed to better understand beliefs that permeate the attitudes of diabetic patients' self-care, under a qualitative methodological approach. Nine diabetic patients participated in the research. A semi-structured interview was the instrument used to collect the data, with the thematic modality content analysis technique used in data treatment. Through such analysis, three issues of significance were found - The influence of beliefs in the conceptualization of diabetes; Beliefs, self-care, and care practices; and The belief in the family role, the media role, and the health professionals' role in self-care. It was observed that the diabetic clients have healthy eating habits and phyto-therapy practices as forms of self-care; and the media, the family, and health professionals as their motivating factors. However, for the promotion of diabetic care, considerations for their beliefs should be included in self-care practices.
\end{abstract}

DESCRIPTORS: Diabetes mellitus. Self care. Education.

\section{CREENCIAS EN EL CUIDADO A DIABÉTICOS - IMPLICACIONES PARA LA PRÁCTICA}

RESUMEN: El objetivo del estudio fue comprender las creencias que impregnan las actitudes de autocuidado de los pacientes diabéticos. Nueve pacientes diabéticos participaron de la investigación. La entrevista semiestructurada se utilizó como instrumento para la recolección de los datos, y la técnica de análisis de contenido, modalidad temática, para su tratamiento. A través del análisis se encontraron tres temas de significación - La influencia de las creencias en el concepto de diabetes; Las creencias, el autocuidado y las prácticas de cuidado; La creencia en el papel de la familia, de los medios y de los profesionales de salud en el autocuidado. Se observó que los pacientes diabéticos utilizan la alimentación saludable como forma de autocuidado; y los medios, la familia y los profesionales de salud, como factores motivadores del mismo. Por lo tanto, para que se promueva la asistencia a los diabéticos, se deben considerar sus creencias en la práctica de autocuidado.

DESCRIPTORES: Diabetes mellitus. Autocuidado. Educación. 


\section{INTRODUÇÃO}

O Diabetes Mellitus (DM) é uma doença crônica, em que grande parte de suas complicações torna o indivíduo incapaz de realizar suas atividades cotidianas, o que pode contribuir para uma diminuição de sua autoestima e, conseqüentemente, afetar sua qualidade de vida.

Essa doença figura entre as quatro principais causas de morte no país, além de ser a principal causa de cegueira adquirida e de estar fortemente associada às doenças coronarianas, renais e amputações de membros inferiores. ${ }^{1}$

A possibilidade do surgimento de tais complicações crônicas é um fato preocupante para os profissionais de saúde que cuidam dos diabéticos, principalmente daqueles cujo comportamento de autocuidado não é incorporado em sua vida diária.

Na prática assistencial deparamo-nos com o impacto que o DM tem sobre a saúde da população e com a dificuldade de adesão dos seus acometidos aos comportamentos preventivos. Nessa perspectiva, o enfermeiro, enquanto profissional de saúde engajado na assistência ao diabético, deve programar novas práticas de cuidado capazes de promover a saúde dos diabéticos, já que a adesão ao tratamento e o autocuidado são pontos frágeis da educação em saúde e que, portanto, merecem ser refletidos profundamente. ${ }^{2}$

Observa-se, dessa forma, o quanto é válido manter o diabético atento à importância da adesão ao tratamento por meio de educação continuada. Para tanto, precisa-se considerá-lo como um ser humano com suas crenças e como essas podem influenciar no modo como se cuida com o diabetes.

Definimos crença como o resultado do domínio da experiência, constituindo-se de convicções não fundadas racionalmente e que modelam a conduta cotidiana. ${ }^{3}$

Fica claro então que, para orientarmos e estimularmos o autocuidado aos diabéticos precisamos conhecer suas crenças e, além disso, fazê-lo conhecer como podem ser decisivas na forma como aprendem a se cuidar - componente cognitivo, decidem sobre como se cuidar - componente afetivo e passam a se cuidar - componente comportamental.

Afirma-se que os costumes sobre as práticas de saúde, os valores e as percepções do paciente/ cliente em relação à doença e ao tratamento são diferentes daqueles pensados pelos profissionais da saúde, já que são dois grupos socioculturais, lingüísticos e psicológicos distintos. Então, fazse necessário conhecer e considerar as práticas populares de saúde para uma maior efetividade e resolutividade do atendimento e até como mais uma opção de autocuidado que podemos discutir e oferecer ao usuário. ${ }^{4}$

Os próprios clientes julgam se a ação de autocuidado é benéfica para eles, e esse julgamento ocorre de acordo com as orientações internas e/ ou externas, que, por sua vez são moldadas pela cultura em que os indivíduos vivem. ${ }^{5}$

A concepção de saúde e o modo como cada pessoa enfrenta a doença são concebidos a partir das experiências pessoais e, essas, guardam uma relação direta com suas crenças e valores os quais são formados ao longo da vida.

Sabe-se que a educação é um dos pontos fundamentais no tratamento do DM, sendo também necessária a motivação do indivíduo para a aquisição de novos conhecimentos e para o desenvolvimento das habilidades nas mudanças de hábitos. A esse respeito teríamos como objetivo geral o bom controle metabólico e melhor qualidade de vida. ${ }^{1}$

Concorda-se com a afirmação acima, entretanto, é preciso conhecer um pouco mais dos diabéticos que cuidamos e, para tanto, deve-se levar em consideração as suas crenças em saúde, a fim de que se possam utilizar estratégias de educação em saúde em consonância com modo de vida. Fazemos deste modo, os seguintes questionamentos: Quais são os comportamentos de autocuidado eleitos pelos diabéticos? Quais as crenças que permeiam o autocuidado em diabetes?

Pressupomos que o conhecimento das crenças dos diabéticos oferecerá relevantes subsídios para uma prática de enfermagem, que possibilitará promover a assistência e o autocuidado desse indivíduo ao longo do processo saúde-doença. Assim, o objetivo desta pesquisa foi conhecer as crenças que permeiam as atitudes de autocuidado dos diabéticos.

\section{MÉTODO}

Trata-se de uma pesquisa descritiva com abordagem qualitativa, a qual possibilita compreender um problema na perspectiva dos sujeitos que o vivenciam, atentando-se para o contexto social em que o evento ocorre.

Foram incluídos no estudo diabéticos de ambos os sexos, a partir de 30 anos de idade, com diagnóstico clínico-laboratorial de DM Tipo 2, 
que estivessem em seguimento regular em uma Instituição de Saúde Privada, localizada no município de Fortaleza-CE e que concordassem em participar da pesquisa.

Utilizou-se o critério de saturação dos dados para a determinação do número de participantes, o que foi alcançado com nove diabéticos entrevistados. Para garantir o anonimato dos participantes empregamos letras: S1, S2, S3, S4, S5, S6, S7, S8 e S9.

A entrevista semi-estruturada individual foi usada como instrumento de coleta de dados. Para sua realização, elaborou-se um roteiro, o qual foi submetido a um pré-teste que comprovou sua adequação para a população investigada. Para tanto, foram feitas as seguintes questões norteadoras: Como é o seu dia-a-dia sendo diabético? O que é ter diabetes? Como você se cuida em diabetes?

Os depoimentos foram gravados e depois transcritos na íntegra para serem lidos cuidadosamente. Em seguida, foram agrupados em temas e analisados conforme análise de conteúdo, modalidade temática, procurando-se analisar o seu conteúdo simbólico, ou seja, descobrir os "núcleos de sentido" que compõem a comunicação.

Obteve-se a aprovação do Comitê de Ética em Pesquisa da Universidade de Fortaleza sob $\mathrm{N}^{\circ}$ 262/2006 para sua implementação. As entrevistas aconteceram após a assinatura de um Termo de Consentimento Livre e Esclarecido dos participantes.

\section{RESULTADOS E DISCUSSÃO}

\section{A influência das crenças na conceituação do diabetes}

Solicitou-se aos participantes que falassem a primeira coisa que pensassem da doença DM. Este foi um momento singular, em que expressaram realmente suas crenças sobre a doença, sem censura, sem pensarem no certo ou no errado. As crenças relacionados à doença foram surgindo, entre elas destacou-se os múltiplos conceitos atribuídos à doença: eu acho que é o sangue fraco [...] A gente não poder trabalhar. Não pode andar no mundo (S3). É o sangue virando água né [...] Quem tem diabetes não pode ser muito feliz não. (S5).

Os depoimentos de S3 e S5 evidenciam o saber popular sobre diabetes como uma doença que não tem cura, que surge devido ao "sangue fraco" ou ao "sangue virando água". Isto sinaliza o modo como os diabéticos percebem a "força" da doença em seus corpos já que não tem cura; em contrapartida, seus corpos ficam à mercê dos desejos da doença ao ponto de transformar sangue em água. Ora, como então "lutar" contra uma força tão avassaladora?

Algumas doenças permanecem arraigadas no folclore do povo, tornando-se populares. Esta popularização pode prejudicar o reconhecimento da doença, seu diagnóstico, manejo e controle da mesma. ${ }^{6}$

Em contra partida, os enfermeiros continuam arraigados às práticas assistenciais que valorizam os achados clínicos e desconsideram os achados populares que se fortalecem com as crenças. Desse modo, não contribuiremos na aproximação dos diabéticos com autocuidado e assim, nossa prática não impactará os indicadores epidemiológicos que retratam os danos à saúde do diabético

Os sentimentos desses diabéticos com relação à sua condição nos levam a inferir que a doença significa mais do que um conjunto de sintomas, possui muitas representações simbólicas e culturais. Afirmamos, assim, a necessidade do conhecimento sobre como as crenças podem influenciar no modo como os diabéticos vislumbram sua condição.

A forma pela qual os sujeitos entendem a realidade vai determinar a sua maneira de se conduzir na vida. ${ }^{7}$ Assim, de acordo com o que o cliente sabe de sua doença, seu real significado, seus riscos e controle de suas atitudes e estilo de vida se encaminharão para a prática no seu cotidiano. Consideramos necessário que o cliente saiba mais sobre a sua doença para que tome atitudes corretas facilitando o seu tratamento, pois se ele mantém um mesmo conhecimento por longo período, isso poderá acomodá-lo a respeito do problema que ele tem. Então, é de extrema importância que eles sejam melhor informados sobre a doença e, assim, tornem-se capacitados para lidar com ela mais ativamente.

\section{As crenças, o autocuidado e as práticas cui- dativas}

Ao longo das entrevistas surgiram depoimentos que apontavam a relação das crenças com as práticas de autocuidado em diabetes. Algumas falas que expressam o que é ter uma alimentação adequada de acordo com as crenças.

Eu tenho cuidado né... pra não comer nada pesado, pra não comer nada coisado assim né, pra não sentir mal... pra diminuir a diabetes né... (S1). 
O meu dia-a-dia é assim, eu sigo a minha dieta... no caso na minha casa, assim, refrigerante só entra se for diet, sorvete também (S2).

Agora a alimentação é que eu acho fraca porque é verdura, fruta e carne moída... gordura de jeito nenhum....Açúcar eu não como... ninguém, come farinha, ninguém, come tapioca (S3).

Eu só faço almoçar e jantar. A doutora diz que é pra me comer três vezes. Deus me livre mulher, se eu for comer três vezes eu vou inchar (S4).

Pode -se perceber no relato de $\mathrm{S} 4$ a evidente distância entre a dieta prescrita e a dieta que é incorporada pelos diabéticos. Por outro lado, os depoimentos de S1 e de S2 mostraram não haver dificuldades em relação à dieta; e para S3 a dieta recomendada parece ter o significado de perder o prazer de comer e beber.

Na sociedade ocidental, a comida não é apenas uma fonte de nutrição, mas tem papéis que estão relacionados com os aspectos sociais, religiosos e econômicos. Para o autor, o alimento é uma parte essencial do modo como a sociedade se organiza e vê o mundo. ${ }^{6}$

Alguns hábitos da sociedade ocidental são tidos como tabus, considerando que alguns alimentos são nocivos, ou mesmo proibindo a ingestão de outros alimentos em determinada fase da vida do indivíduo. É o que está expresso na fala de S4 e S1.

Percebe-se, então, que o conhecimento mútuo dos hábitos alimentares, bem como a adoção de crenças alimentares, expressa pela sua origem, torna a culinária brasileira uma riqueza múltipla de cultura, marcadamente regional, ainda que tenha um denominador comum na combinação "feijão com arroz", como o prato que mais caracteriza os hábitos alimentares. Tal idéia foi colocada por quase todos os participantes e enfatizada na fala de S1.

Entende-se também que a crença influencia diretamente a escolha dos alimentos diários. Desse modo, a alimentação humana parece estar muito mais vinculada a exigências tradicionais do que às próprias necessidades fisiológicas, como fala S3.

Mas, há também as diferenças alimentares existentes na sociedade, como aquelas relacionadas à estrutura social em que o consumo de determinados alimentos está ligado à renda da população, (fala de S2).

As crenças e as práticas relacionadas à dieta são notoriamente difíceis de serem mudadas, mesmo quando interferem com a nutrição adequada. Muitos nutricionistas, enfermeiros e médicos bem- intencionados descobriram esse fato lidando com culturas diferentes das suas. ${ }^{6}$

Não deve-se esquecer que os diabéticos desse estudo são nordestinos, alguns advindos de cidades do interior do Estado do Ceará, cujos hábitos alimentares são determinados pelas suas crenças obtidas pelo aprendizado com seus antecessores que pelo tipo de trabalho, no sertão nordestino, obtinham alimentos de lavoura, do engenho de cana de açúcar,da extração da mandioca.

O tema da alimentação é capaz de gerar indagações que levam a refletir sobre questões fundamentais da antropologia tais como a relação da cultura com a natureza, o simbólico e o biológico. O alimentar-se é um ato vital, sem o qual não há vida possível, mas, ao se alimentar, o homem cria práticas e atribui significados àquilo que está incorporando a si mesmo, o que vai além da utilização dos alimentos pelo organismo. ${ }^{8}$

Com referência ao autocuidado em diabetes, a busca do cuidado alternativo pelos sujeitos demonstra crenças que denunciam a ingestão de fitoterápicos de forma indiscriminada.

Eu faço chá de quebra-pedra que é amargoso [...] Pro diabetes é a mesma coisa, também é muito bom, porque o diabetes não quer nada doce, só quer amargo. [...] Diabetes é só coisa amargosa (S3).

[...] eu tomo o chá da mão-da-vaca [...] A da mãoda-vaca é pra baixar a diabete. [...] Eu já to com vontade de deixar de ficar ou sem as pílulas ou sem o chá (S4).

Eu plantei agora um galhinho que é muito bom - a insulina -é uma plantinha verde... É pra mim tomar o chá dela direto que é muito bom. Eu aprendi com uma conhecida minha que ela tinha diabetes e ela tomava... (S5).

Alguns exemplos da terapia alternativa são: uso de chás tais como: carqueja, mão-de-vaca, insulina, chá-verde e quebra-pedra. $\mathrm{Na}$ fala de S3, ela ainda explora a crença de que o diabetes é marcado como uma doença em que não se pode ingerir nada doce.

Pode-se perceber diante das falas que os tratamentos alternativos aparecem como uma ajuda na terapêutica tradicional. Os resultados ainda são questionáveis e dependem da visão individual dos profissionais. Entretanto, algumas ervas são tradicionalmente usadas para diabetes, sendo seu conhecimento passado de geração para geração, independente da própria indicação que o profissional de saúde faça no atendimento.

O uso de práticas baseadas no saber popular não se encontra apenas na falta de esclarecimentos 
ou de recursos financeiros por parte da população. As crenças e práticas baseadas no saber popular e em experiências empíricas são adotadas como recursos destinados à manutenção da saúde ou cura de doenças. Essas práticas se justificam, principalmente, por meio da crença na ação terapêutica dos recursos utilizados. ${ }^{9}$

O uso de práticas populares no cuidado com a saúde significa a percepção da doença de um modo mais abrangente, promovendo a totalização homem-natureza-cultura. A medicina popular é capaz de oferecer uma resposta integral ao paciente, levando-se em consideração não apenas os aspectos somáticos, mas psicológicos, sociais, espirituais e existenciais. Para muitos médicos, a doença é acima de tudo um fenômeno físico; já para os leigos, a doença se expressa no corpo, mas o ultrapassa indiscutivelmente. ${ }^{10}$

Os achados reforçam a importância dos profissionais conhecerem a fitoterapia como prática complementar no cuidado dos clientes, para que possam orientá-los sobre a forma adequada do cultivo, conservação e preparo das ervas.

Perpassando diferenças sociais, econômicas, espaciais e culturais, pode-se verificar, na vida cotidiana da gente brasileira, a permanência da utilização de práticas medicinais tradicionais e/ou hábitos de se recorrer a tratamentos ritualizados, tais como: chás, xaropes caseiros e remédios fitoterápicos; utilizados em terapêuticas para problemas físicos ou para aqueles a que se atribuem causas simbólicas. ${ }^{11}$

A busca por práticas populares pode indicar uma resistência cultural e um apelo a formas terapêuticas que fazem mais sentido em função da proximidade sociocultural, já que o conhecimento sobre ervas é difundido pela cultura popular, pelas práticas populares e pelo aconselhamento de pessoas, curandeiros e religiosos.

\section{O papel da família, da mídia e dos profissio- nais de saúde no autocuidado}

Os comportamentos de autocuidado dos sujeitos em relação ao diabetes têm um importante componente de motivação familiar. Nas falas a seguir percebemos a relevância do componente familiar nos comportamentos de autocuidado, tendo a família um papel de incentivadora dos comportamentos.

[...] porque a família deve ajudar a pessoa que é diabética, evita na frente dele ou dela a alimentação que ele não pode que é o caso na minha casa.... (S2).
A família tanto se cuida como cuida da outra pessoa, ta sempre ali, fulano tomou o remédio? Lá em casa estão sempre me lembrando porque eu sou um pouco esquecido (S6).

Os depoimentos reforçam a importância da família no cuidado ao diabético e sua influência na condução do tratamento. Nessa relação, a família motiva ações autocuidativas, além de demonstrar sentimentos de afeto, cooperação e solidariedade.

A família é o principal meio de divulgação dessas práticas e têm um importante papel na manutenção da saúde de seus membros e da sua comunidade. De uma forma ou de outra, é a unidade primária da cultura humana e da sociedade. ${ }^{12}$

Sabe-se que a família e os amigos influenciam tanto no controle da doença quanto no seguimento do tratamento, da dieta e na participação em programas regulares de exercícios, como expresso nas falas. É comprovado em estudos, que as pessoas com DM, as quais tiveram apoio adequado de amigos e familiares, aderiram melhor às condutas de autocuidado. Esses estudos relatam que avaliar os meios de apoio do paciente/cliente pode ajudar a identificar suas necessidades de assistência, com o propósito de evitar as complicações em longo prazo. ${ }^{13}$

Os meios de comunicação, em especial a televisão, foram considerados pelos participantes como incentivadores da prática de autocuidado do diabetes. Nas falas encontramos a crença de que a televisão fornece informações sobre a necessidade do autocuidado, incentivando a busca de orientação profissional.

[...] as meninas vê na televisão e disse que viu na televisão sobre a Diabetes e me diz "olhe mãe ta vendo? tá passando na televisão pra pessoa diabetes fazer viu?". (S5).

Porque eu assisto muita televisão e vejo os doutores dizendo que o nosso corpo precisa do açúcar, precisa da gordura, agora não só comer toda hora, todo instante aquilo, mas lá uma vez na vida eu faço (S4).

Para estes participantes a televisão apresenta uma forte influência cultural na apreensão de conhecimentos sobre o diabetes e suas formas de autocuidado. Acreditamos na relação de transferência de conhecimentos específicos da televisão com relação à prática do autocuidado e na sua influência exercida ao ser diabético que se cuida, como descrito nas falas de S4 e S5.

Percebe-se então, que a mídia, particularmente a televisão, opera os sujeitos, na medida em que produz imagens e significações. É capaz de 
empregar saberes que de alguma forma se dirigem à "educação" das pessoas, ensinando-lhes modos de ser e estar na cultura em que vivem.

Atualmente, grandes campanhas televisivas em prol do autocuidado em diabetes têm sido realizadas, porém percebe-se que ainda são insuficientes para que a efetiva prática do autocuidado seja incorporada aos hábitos e comportamentos de todos os diabéticos.

É atribuída ao diabético, muitas vezes, a responsabilidade pelo sucesso ou não do autocuidado, no entanto, precisamos ficar atentos às práticas veiculadas nos meios de comunicação de massa, já que é dentro de um processo quase mágico, veloz e sutil que mensagens - formas simbólicas, dos tipos mais diversos, passam a interagir com as diversas culturas, criando representações e transformando relações. ${ }^{14}$

Além da mídia, o relacionamento entre o profissional de saúde e o cliente é fundamental na orientação nas práticas de autocuidado. Esse profissional é pessoa mais indicada para orientar a respeito dos cuidados.

[...] a doutora disse que é muito bom caminhar né... que eu não caminhava... Eu acredito em Deus e acredito nos médicos em segundo né (S2).

Eu me cuido o que a doutora me explica como é. $O$ que eles me ensinarem, eles me explicam, e tem as consultas e eu vou né (S3).

A doutora me explica como é, no dia que dá, eu gosto de participar das palestras porque é muito animado, eu aprendo (S9).

O profissional de saúde é a pessoa mais indicada para orientar a respeito das práticas de autocuidado que possam garantir a eficácia da adesão ao tratamento, desde que ele respeite as crenças dos clientes, e não realize a ação de informação baseada somente no conhecimento científico. Entende-se que o diabético está apto a aprender a cuidar de si, mas o modo como se ensina tem sido insuficiente porque ele não associa o cuidado à sua crença.

Estudiosos atestaram que um elevado grau de motivação em relação à melhoria e manutenção da saúde nos diabéticos agem em conformidade com aquilo que acreditam ser o melhor a fazer. ${ }^{15}$

As falas apresentadas relatam uma experiência positiva em relação à orientação recebida pelo cliente em sua consulta, percebida na fala de S3.

Sabe-se que o primeiro passo no processo de ensinar/aprender é fazer uma avaliação preliminar. O profissional que assiste o cliente deve ser bastante flexível para adaptar a sua abordagem aos fatores que possam influenciar a capacidade e a vontade do cliente de aprender sobre o diabetes. Assim como descrito na literatura, acreditamos ser importante, para os instrutores tanto reconhecerem as crenças particulares do indivíduo para suas abordagens quanto sua aprendizagem em relação a problemas de saúde em geral. ${ }^{16}$

\section{CONSIDERAÇÕES FINAIS}

Neste estudo foi possível compreender melhor o universo das pessoas com diabetes e, assim, propor alternativas de promoção da assistência. $\mathrm{Na}$ análise dos dados encontramos três temas amplos de significação que demonstraram os conhecimentos, crenças e valores dos sujeitos - A influência dos valores e crenças na conceituação do diabetes; As crenças, o autocuidado e as práticas cuidativas; A crença no papel da família, da mídia e dos profissionais de saúde no autocuidado.

Analisando os resultados de uma forma geral, pode-se considerar que, no caso do grupo investigado, os comportamentos de autocuidado são influenciados pelas crenças e valores. Percebese, também, a incerteza e o desconhecimento de alguns sujeitos sobre a temática, o que é caracterizado por elementos culturais que impõe uma forma própria de ver o DM.

Compete aos profissionais de saúde, especialmente aos enfermeiros, unirem esforços para aperfeiçoarem as formas de tratamento e autocuidado, considerando os aspectos culturais e individuais de seus clientes.

Esses profissionais de saúde nem sempre têm correspondido às expectativas de envolvimento. Percebe-se que o desejo das pessoas com DM é de diálogo e de que sejam criadas possibilidades para que possam efetuar suas escolhas. Essas escolhas nem sempre são aquelas que os profissionais gostariam, mas são aquelas que as pessoas consideram adequadas ao seu viver e que poderão contribuir de algum modo para um viver mais saudável.

Além disso, foi possível perceber no estudo, que não há uma linearidade na maneira de viver com DM. Este é um processo que vai sendo construído atrelado aos outros conhecimentos do viver cotidiano e, portanto, influenciando-os e sendo por eles influenciados. Tal afirmativa é compatível com outros estudos, ${ }^{17}$ evidenciando a dinâmica do viver, com suas múltiplas possibilidades e impossibilidades, mas que pode caminhar para a manutenção ou conquista do viver saudável. 
Os elementos que foram destacados pelos integrantes da pesquisa estiveram mais voltados para aspectos pessoais, relacionados a maneira como incluem o DM em suas vidas. Outros elementos tais como a família, o profissional de saúde e a mídia foram considerados fatores influentes na dinâmica da terapêutica diária do DM. Esses fatos alertam para a necessidade dos programas de autocuidado e da divulgação dos comportamentos preventivos.

Portanto, o tema mostrou-se bastante amplo e passível de reflexões, apresentando subsídios para novos questionamentos, a fim de que a assistência ao cliente diabético seja promovida, considerando-se seus valores e crenças, os quais se apresentam como elementos fundamentais na prática do autocuidado.

\section{REFERÊNCIAS}

1. Sociedade Brasileira de Diabetes. Diagnóstico e classificação do Diabetes Mellitus e tratamento do diabetes mellitus tipo 2 [página da internet], 2000. [acesso em 2006 Jun]. Disponível em: http:/ / www. diabetes.org.br/

2. Ataide MBC. Vivência grupal: estratégia de engajamento no autocuidado e diabetes. [tese]. Fortaleza (CE): Universidade Federal do Ceará; 2004.

3. Birchal TS. Fé, razão e crença na apologia Raymond Sebon: somos cristãos como somos perigordinos ou alemães? Kriterion. 2005 Jan-Jun; 46(111):44-54.

4. Peres DS, Magna JM, Viana LA. Portador de hipertensão arterial: atitudes, crenças, percepções, pensamentos e práticas. Rev Saúde Pública. 2003 Out; 37(5):635-42.

5. Cade NV. Teoria do déficit de autocuidado de orem aplicada em hipertensas. Rev Latino-am Enfermagem 2001 Mai; 9(3):43-50.

6. Helman CG. Cultura, saúde e doença. $4^{\text {a }}$ ed. Porto Alegre (RS): Artmed, 2003. p. 109-45.

7. Teixeira ER. Representações culturais de clientes diabéticos sobre saúde, doença e autocuidado. Rev Enferm UERJ. 1996 Dez; 4(2):163-9.
8. Maciel ME. Cultura e alimentação ou o que têm a ver os macaquinhos de koshima com brillat-savarin? Horiz antropol. 2001 Dez; 7(16):145-56.

9. Leite SN. Além da medicação: a contribuição da fitoterapia para a saúde pública [dissertação]. São Paulo (SP): Universidade de São Paulo; 2000.

10. Laplantine F. Antropologia da doença. São Paulo (SP): Martins Fontes: 1991.

11. Oliveira MFS. Fitoterapia e biodiversidade no Brasil: saúde, cultura e sustentabilidade. Rev Ideas Ambientales [periódico na Internet]. 2005 Abr [acesso em 2006 Nov]; 1(1). Disponível em: http:/ / www.manizales.unal.edu.co/modules/unrev_ ideasAmb/documentos/IAedicion2Art05.pdf

12. SilvaYF. Família e redes sociais: o uso das práticas populares no processo saúde e doença. In: Silva, YF, Froenço MC. Saúde e doença: uma abordagem cultural da enfermagem. Florianópolis (SC): PapaLivro; 1996. p.75-93.

13. Wang C, Fenske MM. Self-care of the adults with non-insulindependent diabetes mellitus: influence of family and frieds. Diabetes Educ 1996 Ago; 22(5):465-70.

14. Roso A et al. Cultura e ideologia: a mídia revelando estereótipos raciais de gênero. Psicol Soc [periódico na Internet]. 2002 Jul-Dez [acesso em 2006 Nov]; 14(2). Disponível em: http: www.scielo.br/scielo. php?script $=$ sci_arttext\&pid $=\mathbf{S 0 1 0 2 7 1 8 2 2 0 0 2 0 0 0 2 0 0}$ $005 \& \operatorname{lng}=\mathrm{pt} \& \mathrm{nrm}=$ iso

15. Apóstolo JLA, Viveiros CSC, Nunes HIR, Domingues HRF. Incerteza na doença e motivação para o tratamento em diabéticos tipo 2. Rev Latino-am Enfermagem. 2007 Aug; 15(4):575-82.

16. Rosemberg C, Peters AL. Instruções ao paciente. In: Davidson MB. Diabetes mellitus: diagnóstico e tratamento. $4^{\mathrm{a}}$ ed. Rio de Janeiro (RJ): Revinter; 2001. p. 305-80.

17. Francioni FF, Silva DGV. O processo de viver saudável de pessoas com Diabetes Mellitus através de um grupo de convivência. Texto Contexto Enferm [periódico na Internet]. 2007 Mar [acesso em 2008 Fev 21]; 16(1):105-11. Disponível em: http:/ /www. scielo.br/scielo.php?script=sci_arttext\&pid=S010407072007000100013\&lng=pt\&nrm=iso.doi:10.1590/ S0104-07072007000100013 